\title{
Empirical relationships of shear wave velocity, SPT-N value and vertical effective stress for different soils in Mashhad, Iran
}

\author{
Azam Ghazi ${ }^{\star}$, Naser Hafezi Moghadas, Hosein Sadeghi, \\ Mohamad Ghafoori, Gholam Reza Lashkaripur
}

Ferdowsi University of Mashhad, Department of Geology, Mashhad, Iran

\author{
Article history \\ Received August 17, 2014; accepted May 18, 2015. \\ Subject classification: \\ Shear wave velocity, Vertical effective stress, Standard penetration test, Empirical relationships, Mashhad, Iran.
}

\begin{abstract}
Shear wave velocity, $\mathrm{V}_{\mathrm{s}}$, is one of the important input parameters in seismic response analysis of the ground. Various methods have been examined to measure the soil $\mathrm{V}_{\mathrm{s}}$ directly. Direct measurement of $\mathrm{V}_{\mathrm{s}}$ is time consuming and costly, therefore many researchers have been trying to update empirical relationships between $\mathrm{V}_{\mathrm{s}}$ and other geotechnical properties of soils such as SPT Blow count, SPT-N. In this study the existence of a statistical relationship between $\mathrm{V}_{\mathrm{S}}$, SPT- $\mathrm{N}_{60}$ and vertical effective stress, $\sigma_{v}{ }^{\prime}$, is investigated. Data set we used in this study was gathered from geotechnical and geophysical investigations reports. The data have been extracted from more than 130 numbers of geotechnical boreholes from different parts of Mashhad city. In each borehole the $\mathrm{V}_{\mathrm{s}}$ has been measured by downhole method at two meter intervals. The SPT test also has performed at the same depth. Finally relationships were developed by regression analysis for gravels, sands and fine grain soils. The proposed relationships indicate that $\mathrm{V}_{\mathrm{s}}$ is strongly dependent on $\sigma_{v}{ }^{\prime}$. In this paper the effect of fine percent also is considered on the $\mathrm{V}_{\mathrm{s}}$ estimation.
\end{abstract}

\section{Introduction}

The first step in the dynamic response analysis of soil is recording the soil key properties such as density, stiffness, damping and maximum shear modulus. The maximum shear modulus of soil is function of the shear wave velocity, $V_{s}$, and soil density $G_{\text {max }}=\rho V_{s}^{2}$. The $V_{s}$ can be determined directly by testing undisturbed soil samples in laboratory or computed using in-situ measurements [Brandenberg et al. 2010]. The $V_{s}$ is also used for the seismic soil classification in building codes. Some of the building codes such as NEHRP, UBC and Iranian seismic code (Iranian Code of Practice for Seismic Resistant Design of Buildings, Standard No. 2800) use the average of $V_{s}$ up to $30-\mathrm{m}$ to classify sites for earthquake engineering design [Borcherdt 1994, Dobry et al. 2000, BHRC 2005].

There are various in-situ methods for measuring $V_{s}$ including seismic refraction survey, Down-hole, cross- hole, seismic CPT, refraction microtremor and the spectral-analysis-of-surface-waves (SASW). It is notable that resolutions of these methods are different and depend on measurement depth, soil condition, interpretation methods and implementation details [Andrus and Stokoe 1997].

The most appropriate methods for measuring $V_{s}$ are in-situ methods. But these methods are usually time consuming, costly, noisy and not applicable at every places. For nearly four decades, researchers have been trying to develop empirical relationships between $V_{s}$ and other geotechnical properties of soils. Previous studies considered different parameters, including geology condition, stratigraphy, geological age, depth, grain size distribution, density, fine percent, standard penetration test value (SPT-N), cone penetration test (CPT) and vertical effective stress, $\sigma_{v}{ }^{\prime}$, to develop empirical relationships [Imai and Tonouchi 1982, Jafari et al. 1997, Hasancebi and Ulusay 2007, Brandenberg et al. 2010, Ghorbani et al. 2012].

In the most relationships, $V_{s}$ is considered as a function of SPT-N values. The SPT is one of the effective tests in quick and low cost assessment of the soil mechanical properties; hence it has received the greatest attention from both academic researchers and professional geotechnical engineers. The purpose of the present study is to assess the correlations between $V_{s}$ and soil properties using statistical methods for collected data throughout the Mashhad City in northeast of Iran (Figure 1). The correlational relationships would be used to assess the site response and to prepare the $V_{s}$ model of the Mashhad depositional basin.

\section{Review of available empirical correlations}

Among the ancient laboratory works, Hardin and Richart [1963] performed one of the first comprehen- 


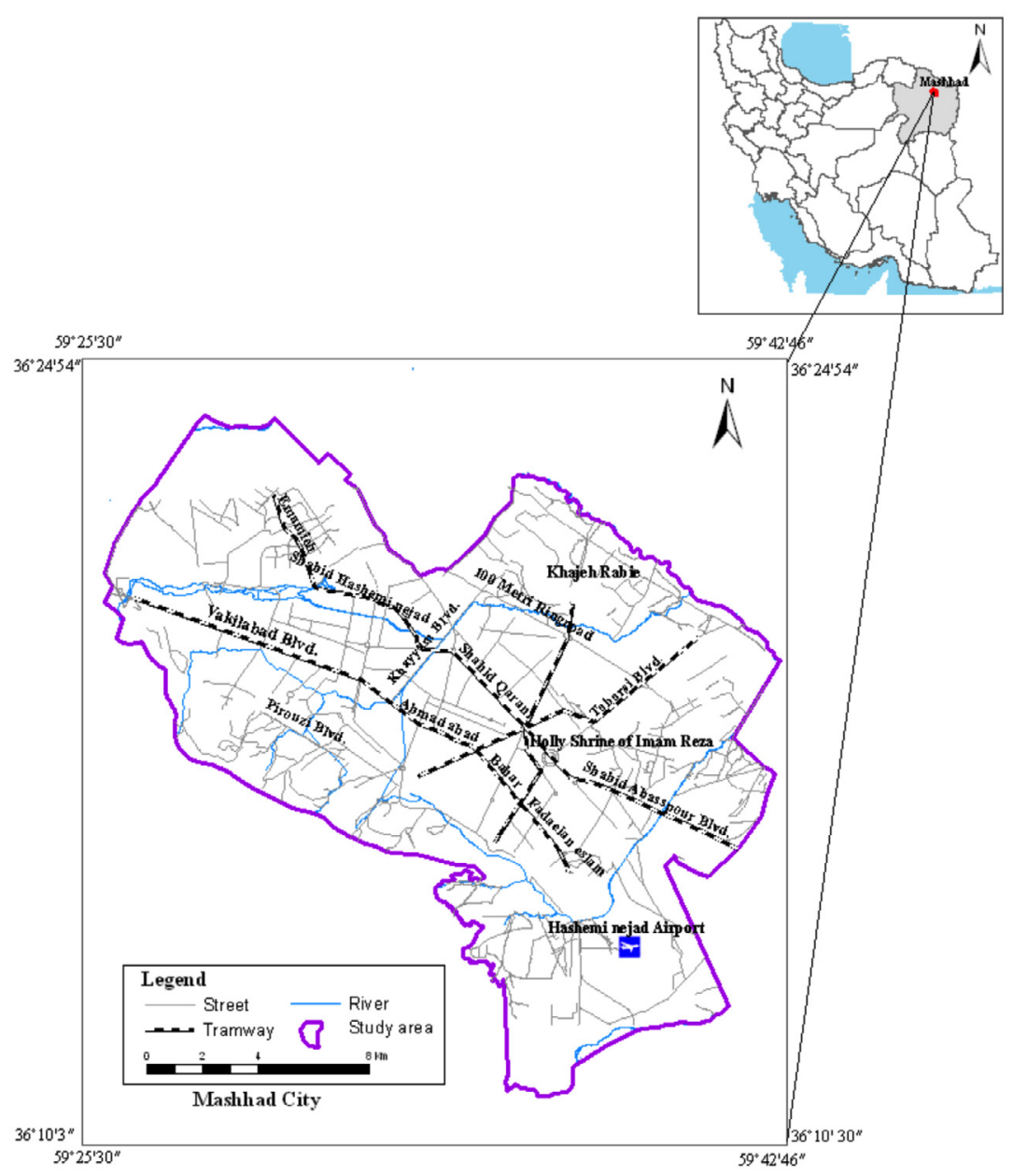

Figure 1. The location map of the study area.

sive laboratory studies in order to determine the $V_{s}$ of different soils, and noted that the $V_{s}$ values would be decreased by increasing the void ratio and would not be affected by the grain size distribution and relative density. Also they simulated the history of field loading condition on preloaded sands and found that the impact of load history on the $V_{s}$ measurements was negligible. Hamilton [1971] assessed the effect of $\sigma_{v}{ }^{\prime}$ on the $V_{s}$ using laboratory tests and presented relations for coarse and fine sands. Lawrence [1965] presented $V_{s}$ as a function of the one-fourth power of the effective hydrostatic stress, $\sigma_{0}{ }^{\prime}$.

Most of the previous studies have focused on the correlations between $V_{s}$ and SPT-N values and just few studies have considered other parameters, including $\sigma_{v}{ }^{\prime}$, total stress, fine percent, depth and CPT. The great majority of correlations assessed in early efforts proposed a power law relationship between SPT-N and $V_{s}$ as follow:

$$
V_{S}=A \cdot N^{B}
$$

where $V_{s}$ is shear wave velocity, $N$ is SPT-N value, $A$ and $B$ are constants determined by statistical regression.

Early studies were often utilized the uncorrected SPT-N value to present relationships [Kanai 1966, Sakai
1968, Imai and Yoshimura 1970, Ohba and Toriumi 1970, Imai and Tonouchi 1982, Lee 1990, Iyisan 1996, Jafari et al. 1997, Jafari et al. 2002]. Pitilakis et al. [1999] suggested relationships between $V_{s}$ and energy-corrected SPT-N for sands and clays by an energy correction factor of $75 \%$. Hasancebi and Ulusay [2007] noted that the best relationships were achieved using uncorrected SPT-N values.

Some researchers have evaluated the impact of soil type on the correlations between $V_{s}$ and SPT-N. Sykora and Stokoe [1983] assessed the influence of soil type on the mentioned correlations and noted that $V_{s}$ are not affected by soil type. Iyisan [1996] also investigated the soil type effects on the correlation between $V_{s}$ and SPT$\mathrm{N}$ in an earthquake-prone area and proposed different relationships for gravels, sands and clays. Lee [1990] and Jafari et al. [2002] also presented different empirical relationships for clays and sands. Kokusho and Yoshida [1997] found that the correlations for gravely soils were dependent on the grain size distribution. Uma Maheswari et al. [2010] evaluated 200 data pairs and found that the effect of soil type is very low.

Campbell and Duke [1976] used 63 data pairs to develop the relationships for both old and recent alluvial soils. They found that the $V_{s}$ values were dependent 


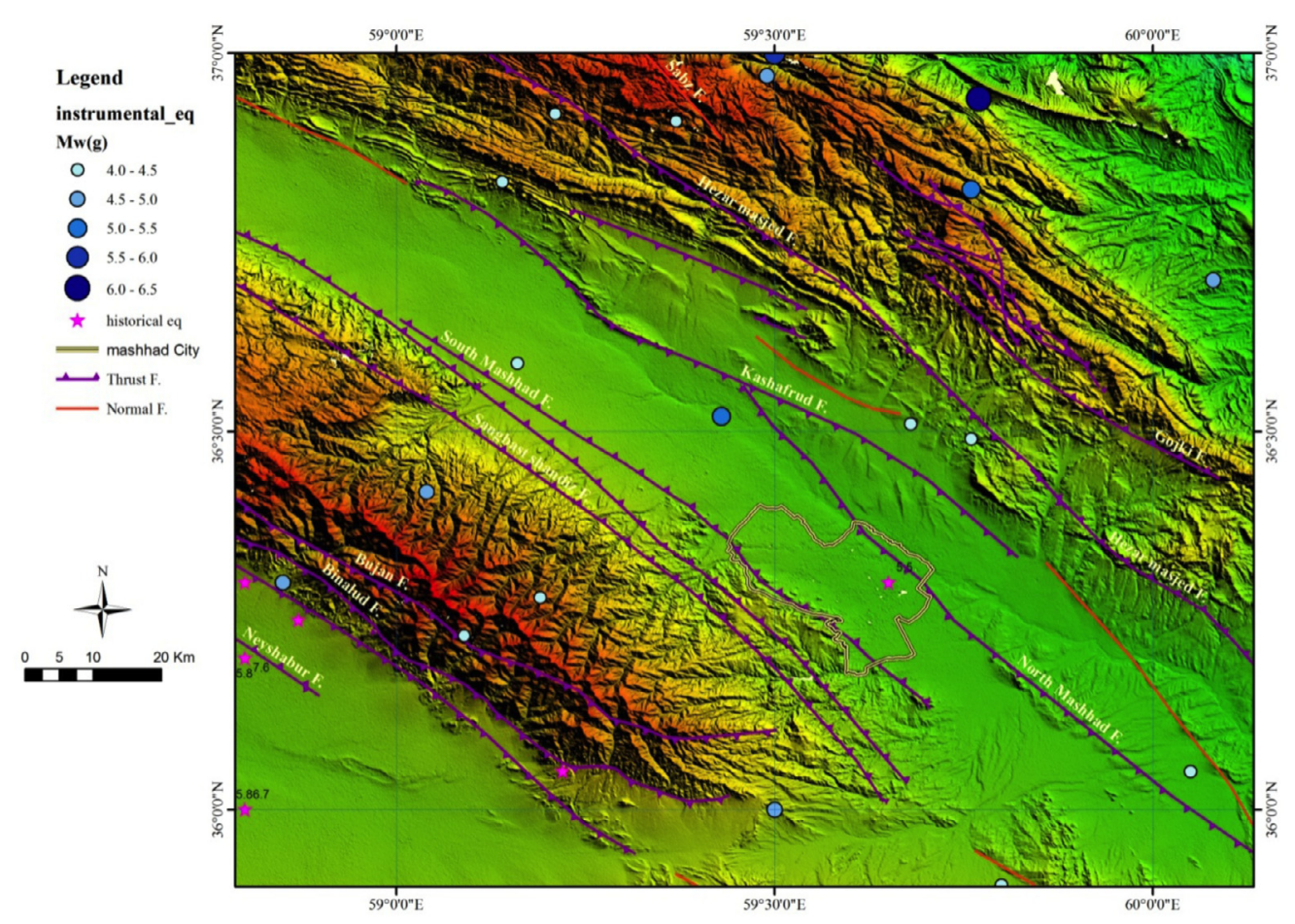

Figure 2. Seismotectonic map of Mashhad city.

only on the depth of soil layers. Sykora and Stokoe [1983] assessed the geological age and found it had no effect on the correlations. Ohta and Goto [1978] proposed a relationship which defines $V_{s}$ as a function of SPT-N, depositional age, depth and lithofacies. Andrus et al. [2009] and Hayati and Andrus [2009] developed the relationships between $V_{s}$, SPT and CPT values for sands with different ages.

Shibata [1970] investigated the results of previous studies to obtain a relationship between $V_{s}$ and SPT-N. He combined the various relationships and found that $V_{s}$ was not dependent on both porosity and $\sigma_{v}{ }^{\prime}$. Sykora and Stokoe [1983] evaluated the effect of total overburden stress, $\sigma_{v}$, and $\sigma_{v}{ }^{\prime}$ on the correlation of $V_{s}$, SPT-N and found that $\sigma_{v}{ }^{\prime}$ was more effective than $\sigma_{v}$. Brandenberg et al. [2010] developed the relationships which estimated $V_{s}$ as a function of SPT-N and $\sigma_{v}{ }^{\prime}$ for the sands, silts and clay soils. Akin et al. [2011] proposed the correlations between $V_{s}$, depth and SPT-N values for different type soils. Ghorbani et al. [2012] used previous published studies to compile a database including the $V_{s}$, $\sigma_{v}, \sigma_{v}{ }^{\prime}$ and SPT-N values. They proposed multivariate relationships between $V_{s}$, corrected SPT-N and $\sigma_{\nu}{ }^{\prime}$.

\section{Geological setting and database}

Mashhad city stands on the alluvial plain which is surrounded by the Kopet-Daq Mountains on the north and the Binaloud Mountains on the south. Geologically, the basement of the plain is composed of Neogene and pre-Neogene rocks in the central and northern parts, and granodiorite, ultrabasic, schist and phyllite rocks in southern and west southern parts. The Quaternary fluvial and floodplain deposits above the basement rocks. Based on the deep boreholes and geophysical studies of Mashhad plain, the thickness of Quaternary deposits reaches to more than $250 \mathrm{~m}$ in the central part of the city.

Mashhad city is surrounded by active faults of Kashafrud, North Mashhad and South Mashhad, and is located in the high seismic hazard zone of Iran [BHRC 2005]. Sesimotectonic map of Mashhad city is presented in Figure 2.

The database contents include information of more than 130 boreholes with depth of 20 to $80 \mathrm{~m}$. Geographical distribution of the boreholes in the study area is shown in Figure 3. $V_{s}$ values were measured at $2 \mathrm{~m}$ intervals using downhole method.

Downhole seismic test is one of the appropriate tests for determining the in-situ profile of body wave velocity with depth. The test would be performed in single borehole with one or two geophone receivers. Standard test methods for downhole seismic testing are explained in ASTM D7400-08 [ASTM 2008]. In this study, the tests were performed using three-component geophone and RAS-24 digital seismograph. An impulse plank source was placed on the ground at $3 \mathrm{~m}$ away from the top of borehole and the single receiver swept the total length of borehole. The shear wave source was a $5 \mathrm{~kg}$ sledge hammer that horizontally hits both ends of wooden beam with steel end plate that was coupled to the ground by weighting it down with filled gunnysacks. The $V_{s}$ was computed at distances of $2 \mathrm{~m}$ by measuring the distance and the travel time of the wave. 


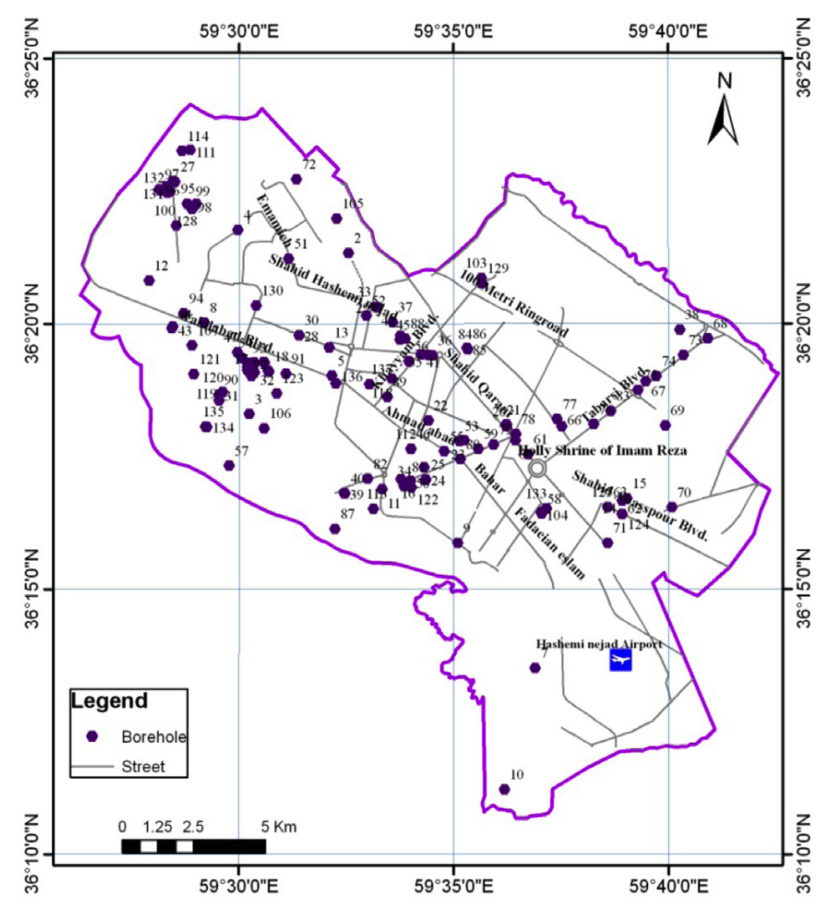

Figure 3. Location of geotechnical boreholes.

Other properties, including SPT-N value, soil texture, unit weight, natural moisture content, fine percent and Atterberg limits and groundwater table also were determined in the all boreholes. Properties of different types of soils are summarized in Table 1 by $V_{s}$ class which was based on previous studies of authors [Ghazi et al. 2014]. Maximum values of $N_{60}$ and unit weight, and minimum values of moisture content are observed in gravely soils. Geological logs with SPT and downhole test results for two boreholes are shown in Figure 4. For the statistical analyses of the present study, only the cases were selected that SPT-N and $V_{s}$ were recorded in the same depth. A total 1500 cases were used in statistical analysis. The frequency distribution of used data based on soil type is shown in Figure 5.

\section{Data analysis and results}

\subsection{Correction of SPT-N value}

SPT test results are affected by various factors such as equipments, $\sigma_{v}{ }^{\prime}$, and soil conditions. There are different equations for correction SPT-N values. In the present study we used McGregor and Duncan's equation that is the most comprehensive equation for the SPT-N correction [McGregor and Duncan 1998]:

$$
N_{60}=\left(C_{B} C_{C} C_{R} C_{B F} C_{S} C_{A} C_{E}\right) N_{\text {field }}
$$

where $C_{B}$ is borehole diameter correction factor, $C_{R}$ is rod length correction factor, $C_{E}$ is energy correction factor, $C_{S}$ is liner correction factor, and $C_{C}, C_{B F}$ and $C_{A}$ are hammer cushion correction factor, blow count frequency correction factor and anvil correction factor, respectively. A borehole diameter correction factor of 1.0 was applied because in rotary drilling, the borehole diameter is $<116 \mathrm{~mm}$. $C_{R}$ was applied based on the information in Table 2. Most of the consulting companies in Iran use a safety hammer with an efficiency of $60 \%$, therefore $C_{E}$ of $60 \%$ was applied. $C_{S}$ of 1.0 was applied because the SPT sampler is not usually fit with the liner. $C_{C}, C_{B F}$ and $C_{A}$ were neglected because of the lack of efficient information.

In this study we use the common overburden cor-

\begin{tabular}{|c|c|c|c|c|c|c|c|c|c|}
\hline$V_{s}$ class & Soil & $N_{60}$ & Yd & $\mathbf{w}$ & $V_{s}$ class & Soil & $N_{60}$ & Yd & $\mathbf{w}$ \\
\hline \multirow{4}{*}{$<300$} & Clay & $23 \pm 11$ & $16.2 \pm 1$ & $12.6 \pm 3$ & \multirow{4}{*}{$750-950$} & Clay & $55 \pm 20$ & $17.3 \pm 1$ & $15.2 \pm 4$ \\
\hline & Silt & $16 \pm 7$ & $16.9 \pm 1$ & $8.8 \pm 5$ & & Silt & $45 \pm 13$ & $17.4 \pm 1$ & $18.4 \pm 4$ \\
\hline & Sand & $29 \pm 14$ & $17.1 \pm 1$ & $5.2 \pm 3$ & & Sand & $70 \pm 30$ & $17.7 \pm 1$ & $5.8 \pm 3$ \\
\hline & Gravel & $39 \pm 18$ & $18.6 \pm 1$ & $4.7 \pm 2$ & & Gravel & $75 \pm 39$ & $19.1 \pm 1$ & $5.4 \pm 3$ \\
\hline \multirow{4}{*}{$300-500$} & Clay & $26 \pm 15$ & $16.5 \pm 1$ & $13.4 \pm 4$ & \multirow{4}{*}{$>950$} & Clay & $52 \pm 22$ & $17.4 \pm 1$ & $15.5 \pm 4$ \\
\hline & Silt & $27 \pm 12$ & $17.6 \pm 1$ & $12.9 \pm 3$ & & Silt & - & - & - \\
\hline & Sand & $43 \pm 22$ & $17.3 \pm 1$ & $6.1 \pm 3$ & & Sand & $75 \pm 31$ & $17.7 \pm 1$ & $6 \pm 2$ \\
\hline & Gravel & $49 \pm 25$ & $18 \pm 1$ & $5.7 \pm 4$ & & Gravel & $77 \pm 39$ & $19.4 \pm 2$ & $5.4 \pm 3$ \\
\hline \multirow{4}{*}{$500-750$} & Clay & $39 \pm 23$ & $16.8 \pm 1$ & $14.2 \pm 5$ & & & & & \\
\hline & Silt & $38 \pm 22$ & $16.2 \pm 1$ & $17.4 \pm 6$ & & & & & \\
\hline & Sand & $56 \pm 27$ & $17.4 \pm 1$ & $5.8 \pm 3$ & & & & & \\
\hline & Gravel & $58 \pm 25$ & $18.5 \pm 1$ & $5.4 \pm 3$ & & & & & \\
\hline
\end{tabular}

Table 1. Median \pm standard deviation values of soil properties, $V_{s}$ class is shear wave velocity in $\mathrm{m} / \mathrm{s} N_{60}$ is SPT-N value corrected for energy in count per 30 centimeters, $\mathrm{Yd}$ is dry density in $\mathrm{KN} / \mathrm{m}^{3}$ and $\mathrm{w}$ is moisture content in percent. 
rection equations for correcting $V_{s}$ and $N_{60}$ that is mentioned in Equation (3) and Equation (4).

$$
\begin{aligned}
\left(N_{l}\right)_{60} & =\left(\frac{P_{a}}{\sigma_{v}^{\prime}}\right)^{n} \cdot N_{60} \\
V_{S l} & =\left(\frac{P_{a}}{\sigma_{v}^{\prime}}\right)^{m} \cdot V_{S}
\end{aligned}
$$

where $P_{a}$ is reference pressure and equals to $100 \mathrm{kPa}$, $\sigma_{v}{ }^{\prime}$ is vertical effective stress and the exponents $\mathrm{n}$ and $\mathrm{m}$ are empirical constants that depend on soil type, cementation, and plasticity index. The exponents $\mathrm{n}$ and $\mathrm{m}$ are often assumed 0.5 and 0.25 respectively.

\subsection{Statistical analysis}

Equation (5) which is the rearrangement of Equations (1), (3) and (4) is used in this study:

$$
\left(\frac{P_{a}}{\sigma_{v}{ }^{\prime}}\right)^{m} \cdot V_{S}=A \cdot\left(\frac{P_{a}}{\sigma_{v}{ }^{\prime}}\right)^{n} \cdot N_{60}^{B}
$$

By taking natural logarithms of Equation (5), the regression form of Equation (6) which is utilized in this study is obtained as:

$$
\operatorname{Ln} V_{S}=\beta_{0}+\beta_{1} \operatorname{Ln}\left(N_{60}\right)+\beta_{2} \operatorname{Ln}\left(\frac{P_{a}}{\sigma_{v}^{\prime}}\right)+\varepsilon
$$

where $V_{S}$ (average shear wave velocity) is in $\mathrm{m} / \mathrm{s}, \sigma_{v}{ }^{\prime}$ is in $\mathrm{kPa}$ and $N_{60}$ is in blow per 30 centimeters. $\beta_{0}, \beta_{1}$ and $\beta_{2}$ are the regression constants, and $\varepsilon$ is standard error.

The regression was performed using linear multiple regression algorithm in SPSS (Statistical Package for the Social Sciences). Linear Regression estimates the coefficients of the linear equation, involving one or more

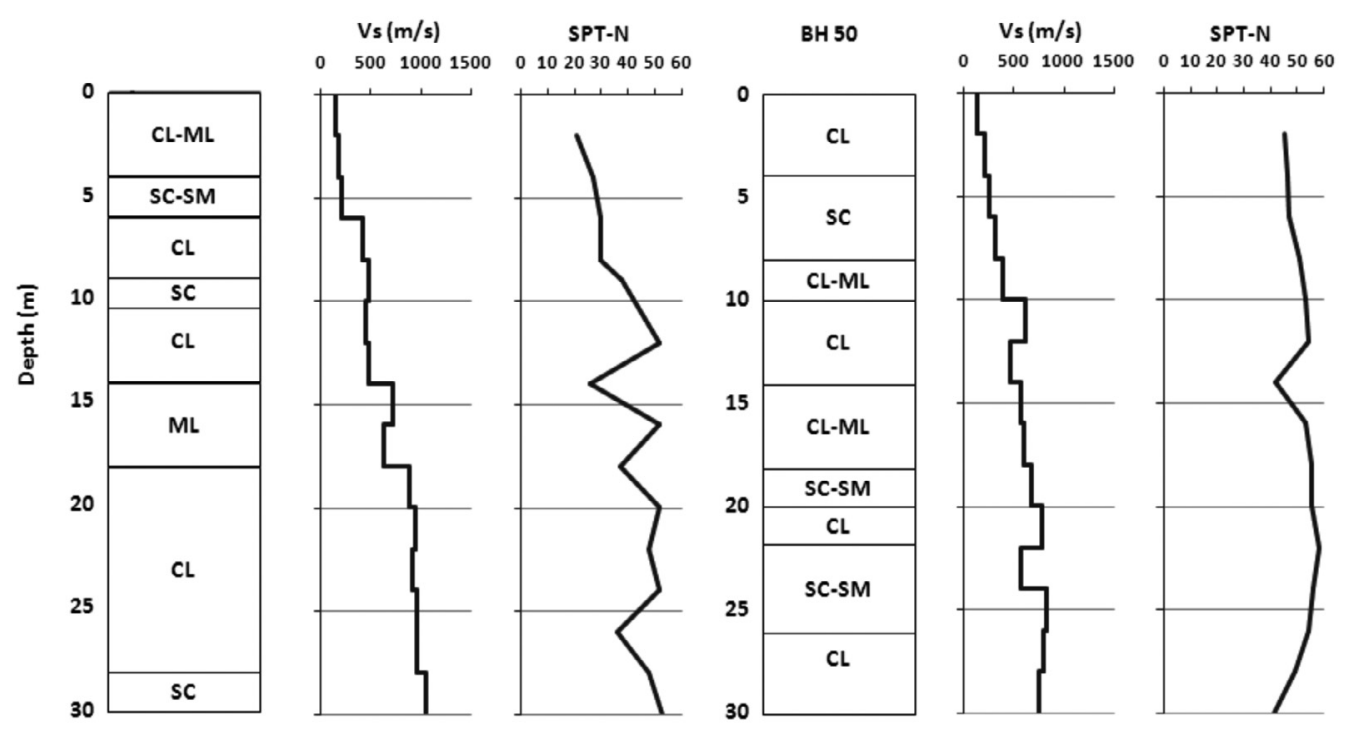

Figure 4. Geology, shear wave velocity and SPT-N profiles at two different sites (Soils are classified based on The Unified Soil Classification System. CL: Lean clay; CL-ML: Silty clay; ML: Lean silt; SC: Clayey sand; SC-SM: Silty, clayed sand).

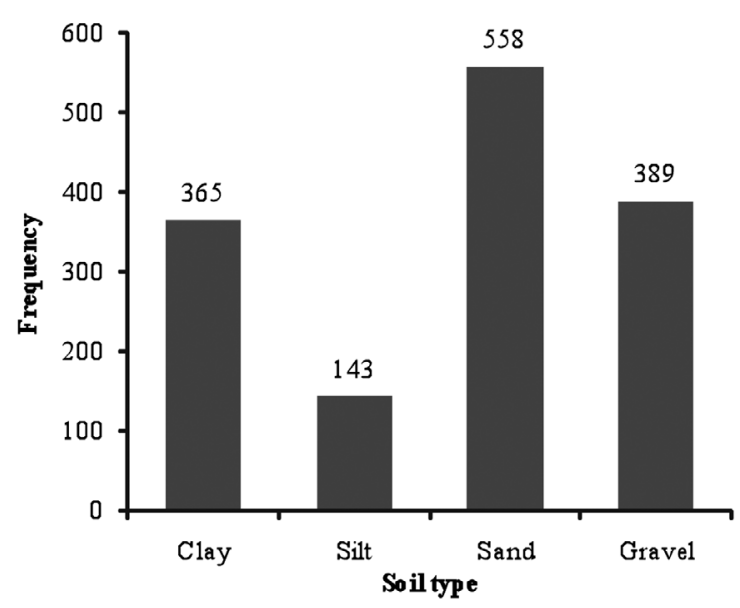

Figure 5. Frequency of data point based on soil type.

\begin{tabular}{cc}
$\begin{array}{c}\text { Rod length } \\
(\mathbf{m})\end{array}$ & $\begin{array}{c}\text { Correction } \\
\text { factor }\end{array}$ \\
$<3$ & 0.75 \\
$3-4$ & 0.8 \\
$4-6$ & 0.85 \\
$6-10$ & 0.95 \\
$>10$ & 1 \\
\hline
\end{tabular}

Table 2. Rod length correction factors [Youd et al. 2001]. 
independent variables that predict the best value of the dependent variable.

Using Equation (6) following regressions was obtained for gravels, sands and fine grain soils:

$$
\begin{aligned}
& \operatorname{Ln} V_{S}=5.43+0.192 \operatorname{Ln}\left(N_{60}\right)-0.246 \operatorname{Ln}\left(\frac{P_{a}}{\sigma_{v}^{\prime}}\right) \\
& R^{2}=0.748 \text { Gravely soils }
\end{aligned}
$$

$$
\begin{aligned}
& \operatorname{Ln} V_{S}=5.51+0.156 \operatorname{Ln}\left(N_{60}\right)-0.279 \operatorname{Ln}\left(\frac{P_{a}}{\sigma_{v}^{\prime}}\right) \\
& R^{2}=0.745 \text { Sandy soils }
\end{aligned}
$$

$$
\begin{aligned}
& \operatorname{Ln} V_{S}=5.69+0.118 \operatorname{Ln}\left(N_{60}\right)-0.242\left(\frac{P_{a}}{\sigma_{v}^{\prime}}\right) \\
& R^{2}=0.629 \text { Fine grain soils }
\end{aligned}
$$

Standard errors of the regressions for gravel, sand and fine grain soils are equal to $0.146,0.170$ and 0.151 respectively. $\operatorname{Ln}\left(V_{s}\right)$ versus $\operatorname{Ln}\left(N_{60}\right)$ and $\operatorname{Ln}\left(V_{s}\right)$ versus
$\operatorname{Ln}\left(\frac{P_{a}}{\sigma^{\prime}}\right)$ are plotted for different soils and are shown in Figure 6. Median regression lines corresponding to the median, median plus and minus of $\operatorname{Ln}\left(\frac{P_{a}}{\sigma_{v}^{\prime}}\right)$ and $\operatorname{Ln}\left(N_{60}\right)$ are plotted through the data points.

There are so many methods for validation of the regression relationship. One of these methods is the residual analysis. Graphical residual plots including histogram of the residual, probability-probability (p-p) plot of regression standardized residual and studentized residual plot for gravel, sand and fine grain soils are shown in Figure 7. Histogram of the residual checks whether the variance is normally distributed. A symmetric bell-shaped histogram which is evenly distributed around zero indicates that the normality assumption is likely true as it seen in our plots. If residuals are not normally distributed, the model is violated. A P-P plot compares the empirical cumulative distribution function of a variable with a specified theoretical cumulative distribution function. This plot also shows whether the residuals or error terms are normally distributed or
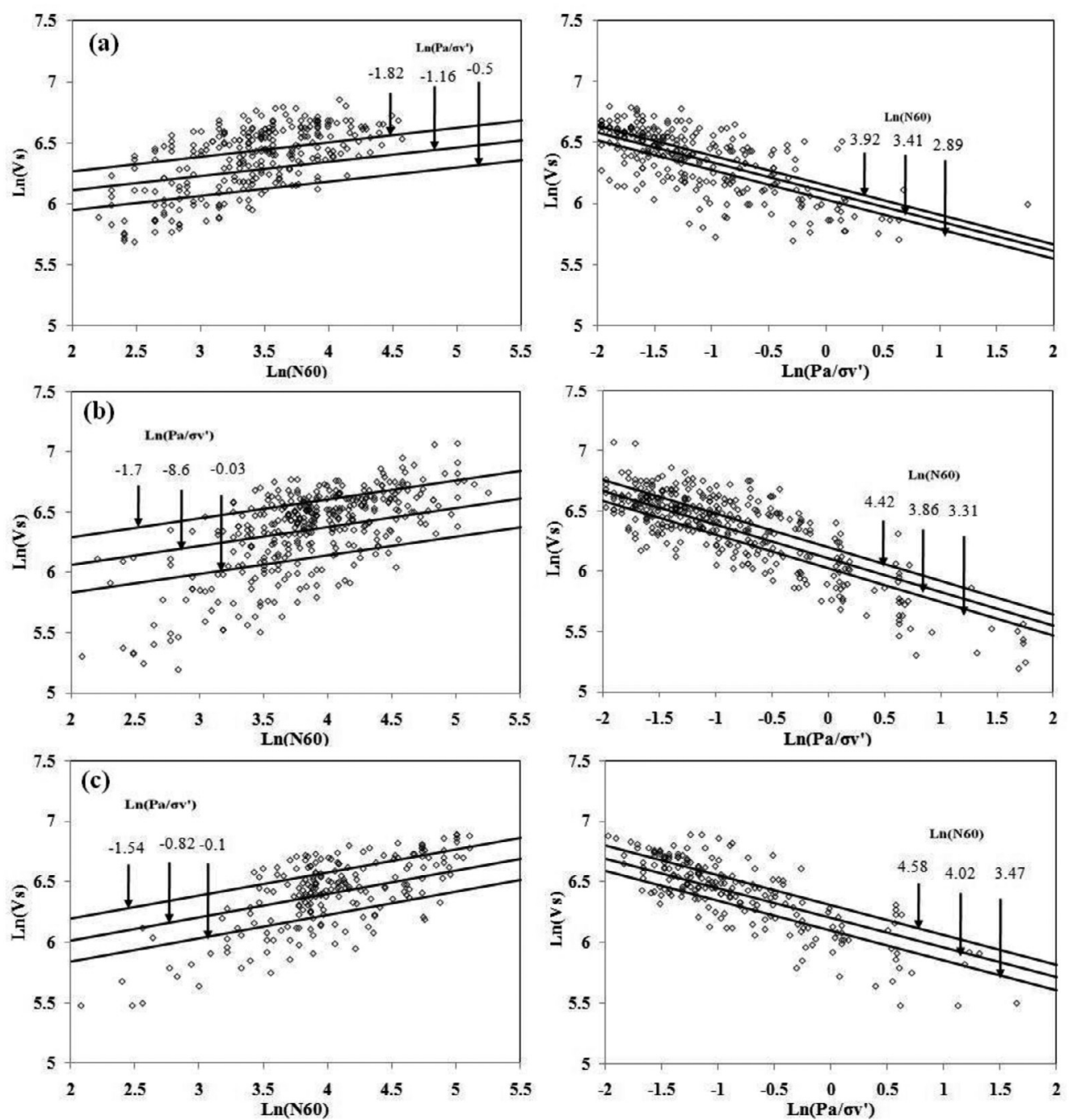

Figure 6. Graphical form of regression equations for (a) fine grain soil, (b) sandy soils and (c) gravely soils, With trend lines corresponding to the mean and mean plus and minus of $\operatorname{Ln}\left(\frac{P_{a}}{\sigma^{\prime}}\right)$ and $\operatorname{Ln}\left(N_{60}\right)$. 

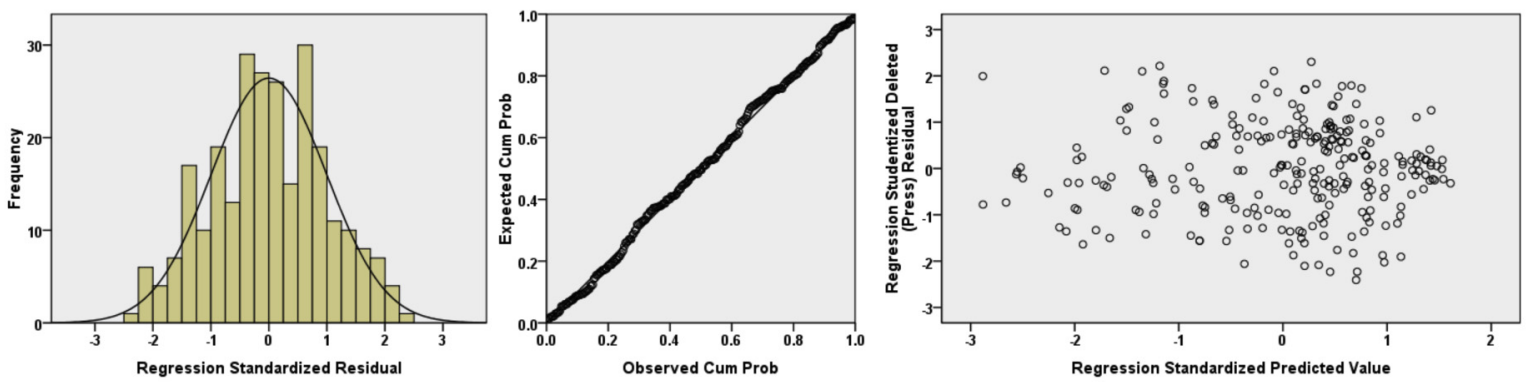

(a)
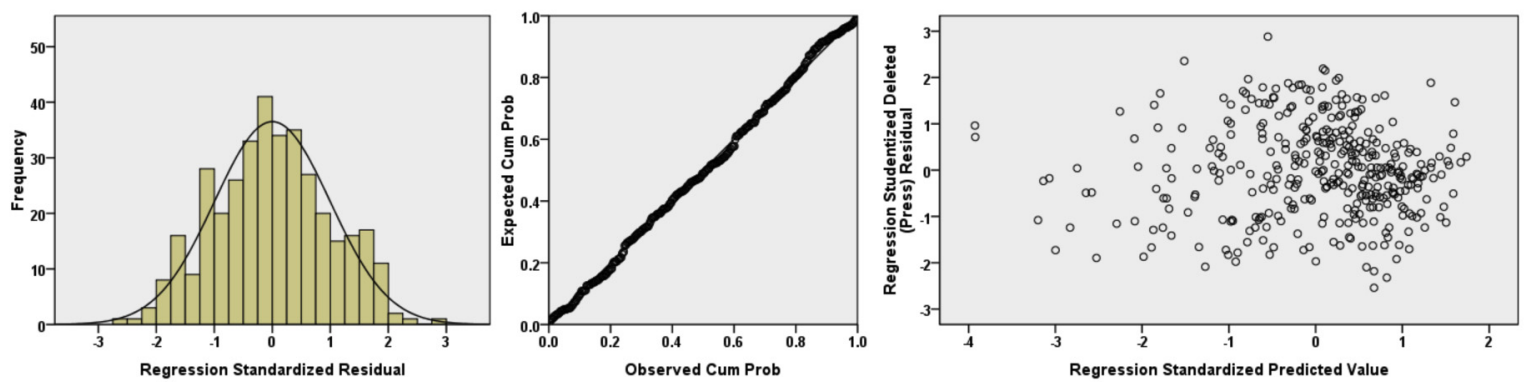

(b)
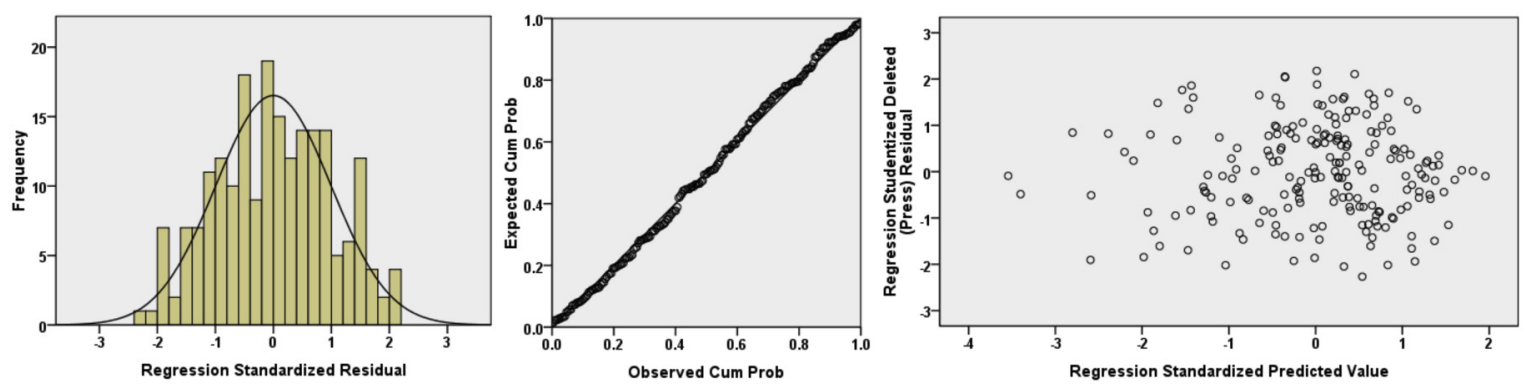

(c)

Figure 7. histogram of the residual, probability-probability (p-p) plot of regression standardized residual and studentized residual plot for (a) fine grain soil, (b) sandy soils and (c) gravely soils.

not. The points should be close to a diagonal line for normally distributed data. Therefore, the validity of presented regression analysis is approved. Also quality of the regression can be evaluated using residual plot. In this plot, the studentized deleted residual is plotted against the standardized estimated values of $V_{s}$ variable. The standardized residual is the residual divided by its standard error. Standardizing is a method for transforming data so that, the mean is equal to zero and the standard deviation is equal to one. The studentized deleted residual is the residual that would be obtained if the regression was re-run omitting that observation from the analysis. For the good regression, the scatter plot of the residuals should be horizontal and random.

Measured $V_{s}$ and estimated $V_{s}$ are compared in Figure 8 for each correlation in order to assess the performance of the regression models. Data points are scattered between lines 1:0.65 and 1:1.5. Majority of the data points are plotted close to the line 1:1. The data points with $V_{s}$ of less than $500 \mathrm{~m} / \mathrm{s}$ are overestimated while the data points with $V_{s}$ of more than $800 \mathrm{~m} / \mathrm{s}$ are underestimated.

\subsection{Influence of fine percent on $\mathrm{V}_{\mathrm{s}}$ estimation}

One of the effective parameters on SPT-N value is fine percent (passing No. 200), especially in coarse grain soils. In this study, the effect of fine percent was also evaluated. For this purpose, all data were classified by the fine percent regardless of soil type. The classification boundaries were considered based on the unified soil classification. At first all data were divided into the four categories of $<5,5-12,12-50$ and more than 50 . There was a few data into first class $(<5)$, therefore two first classes were merged together and the class of $<12 \%$ fine percent was considered. The regression models and adjusted $\mathrm{R}^{2}$ for all three groups are presented in Table 3.

Results of the regressions are shown in Figure 9. Coarse soils show less $V_{s}$ than fine soils in the low values of N-SPT. By increasing N-SPT, the $V_{s}$ values of coarse soil increase further rather than fine soils. It is because of the inherent ability of fine soils in transferring the dynamical energy which is independent to the density and void ratio of soils. All curves were determined according to $\frac{P_{a}}{\sigma_{v}^{\prime}}=1$. For estimating the real $V_{s}$, the obtained $V_{s}$ values from the mentioned curves 


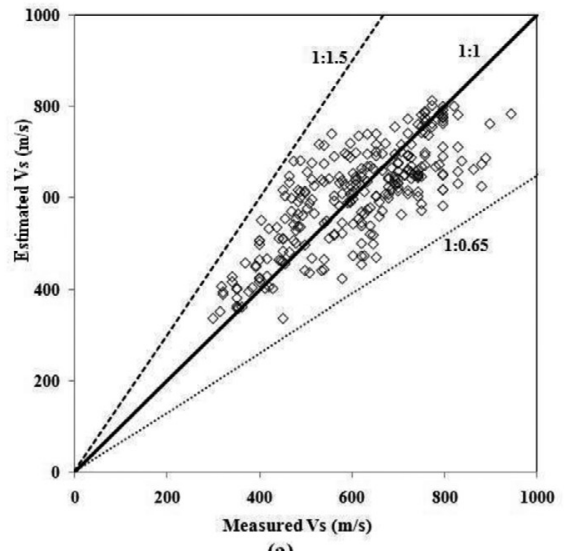

(a)

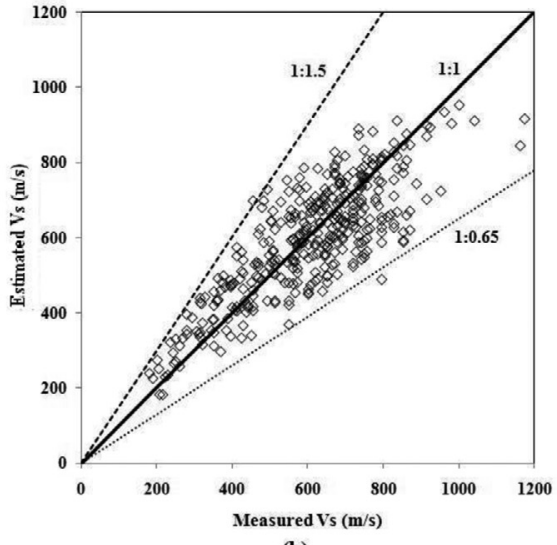

(b)

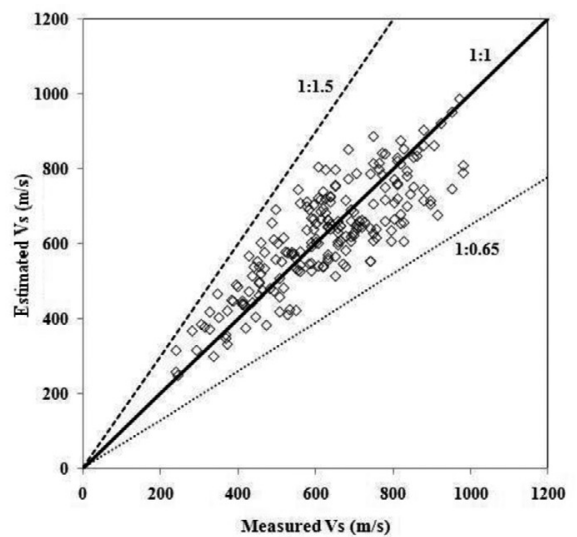

(c)

Figure 8. Measured versus estimated $V_{s}$ for (a) fine grain soil, (b) sandy soils and (c) gravely soils with lines of 1:1.5, 1:1 and 1:0.65.

Adjusted $\mathbf{R}^{2}$

Regression model

$$
\begin{aligned}
& \operatorname{Ln} V_{S}=5.25+0.234 \operatorname{Ln}\left(N_{60}\right)-0.287 \operatorname{Ln}\left(\frac{P_{a}}{\sigma_{v}^{\prime}}\right) \\
& \operatorname{Ln} V_{S}=5.52+0.159 \operatorname{Ln}\left(N_{60}\right)-0.257 \operatorname{Ln}\left(\frac{P_{a}}{\sigma_{v}^{\prime}}\right) \\
& \operatorname{Ln} V_{S}=5.69+0.118 \operatorname{Ln}\left(N_{60}\right)-0.242 \operatorname{Ln}\left(\frac{P_{a}}{\sigma_{v}^{\prime}}\right)
\end{aligned}
$$

Soil groups (based on fine percent)

$\operatorname{Ln} V_{S}=5.25+0.234 \operatorname{Ln}\left(N_{60}\right)-0.287 \operatorname{Ln}\left(\frac{P_{a}}{\sigma_{v}^{\prime}}\right)$
$0.701 \quad \operatorname{LnV}_{S}=5.52+0.159 \operatorname{Ln}\left(N_{60}\right)-0.257 \operatorname{Ln}\left(\frac{P_{a}}{\sigma_{v}^{\prime}}\right)$
0.629
$\operatorname{Ln} V_{S}=5.69+0.118 \operatorname{Ln}\left(N_{60}\right)-0.242 \operatorname{Ln}\left(\frac{P_{a}}{\sigma_{v}^{\prime}}\right)$

Table 3. Regression models and adjusted $\mathrm{R}^{2}$ for all groups that are divided based on fine percent, $\operatorname{Ln} V_{S}$ is natural logarithm of shear wave velocity, $\operatorname{Ln}\left(N_{60}\right)$ natural logarithm of N-SPT corrected for energy, $\frac{P_{a}}{\sigma^{\prime}}$ is vertical effective stress factor.

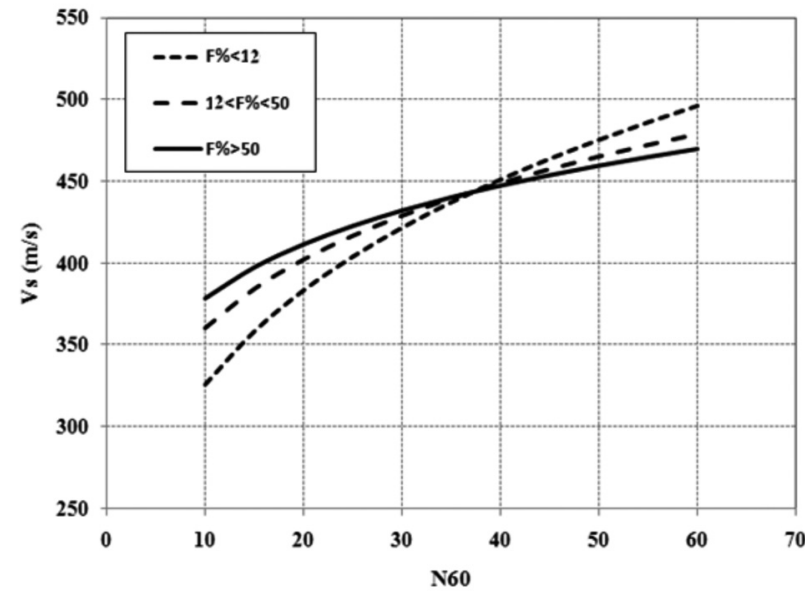

Figure 9. $N_{60}$ and $V_{s}$ relations for $\frac{P_{a}}{\sigma_{v}^{\prime}}=1$ as function of fine percent (F).

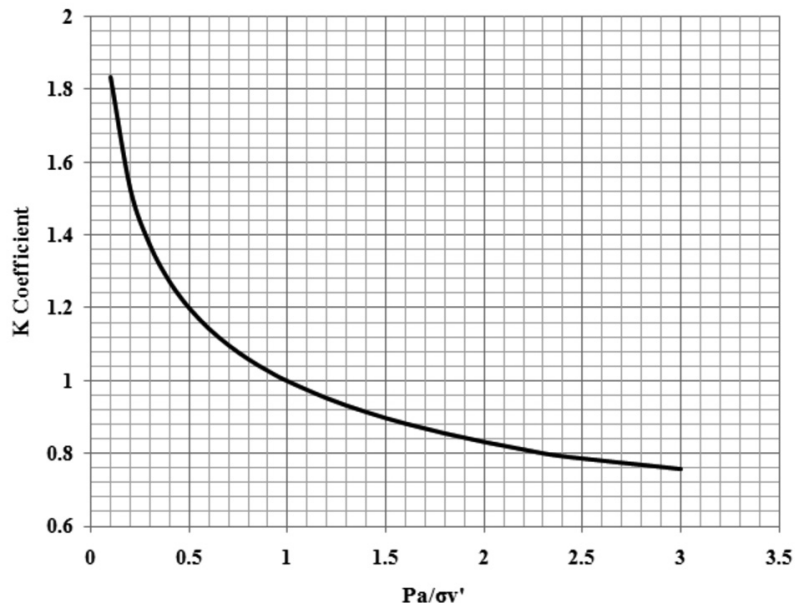

Figure 10. Curve of correction coefficient for determining real $V_{s}$ for all kinds of soil. 
must be multiplied by $\mathrm{K}$ coefficient which is shown in Figure 10.

\section{Discussion}

\subsection{Relative impact of $\mathrm{N}_{60}$ and $\sigma_{v}{ }^{\prime}$ on regression}

When a multiple regression analysis carried out on variables, the software gives both unstandardized coefficients and standardized coefficients. The standardized coefficients are useful to find the contribution of each independent variable on estimating the dependent variable, when the variables are measured in different units of measurement. Standardization of each variable is done by software before regression analysis. For the purpose of this, the mean of variable is subtracted from each value of variable and then the difference value is divided by the standard deviation of the variable. The absolute coefficient value close to 1.0 shows a strong dependency. The standardized correlation coefficients of $N_{60}$ and $\sigma_{v}{ }^{\prime}$ for each soil categories are given in Table 4 in order to show their contribution on the $V_{s}$ estimation. In all three models, the influence of $\sigma_{v}{ }^{\prime}$ on estimating of $V_{s}$ is stronger than the influence of $N_{60}$.

For assessing the influence of $N_{60}$ and $\sigma_{v}{ }^{\prime}$ a simple

\begin{tabular}{lcc} 
& \multicolumn{2}{c}{ Variable } \\
\cline { 2 - 3 } Soil category & $\operatorname{Ln}\left(N_{60}\right)$ & $\operatorname{Ln}\left(\frac{P_{a}}{\sigma_{v}^{\prime}}\right)$ \\
\hline Gravely soils & 0.368 & -0.610 \\
Sandy soils & 0.257 & -0.692 \\
Fine grain soils & 0.239 & -0.622 \\
\hline
\end{tabular}

Table 4. Standardized correlation coefficients of $N_{60}$ and $\sigma_{v}{ }^{\prime}$.

linear regression was also performed between $\operatorname{Ln} V_{S}$ and $L n N_{60}$ using the form of Equation (10) for all soil categories. The residuals of the regression model are plotted versus $\operatorname{Ln}\left(\frac{P_{a}}{\sigma_{v}^{\prime}}\right)$ in Figure 11 .

$$
\operatorname{Ln} V_{S}=\alpha_{0}+\alpha_{1} \operatorname{Ln}\left(N_{60}\right)+\varepsilon
$$

The bias of residuals is clearly seen in the mentioned figure. The negative residuals are seen at the low values of $\sigma_{v}{ }^{\prime}$ and the positive residuals are seen at the high values of $\sigma_{v}{ }^{\prime}$. The negative residuals indicate the underestimation of $V_{s}$ whereas the positive residuals indicate the overestimation of $V_{s}$. Therefore, neglecting of the $\sigma_{v}{ }^{\prime}$ in the regression analysis can cause the significant error in the $V_{s}$ estimation, implying the better $V_{s}$ estimation using

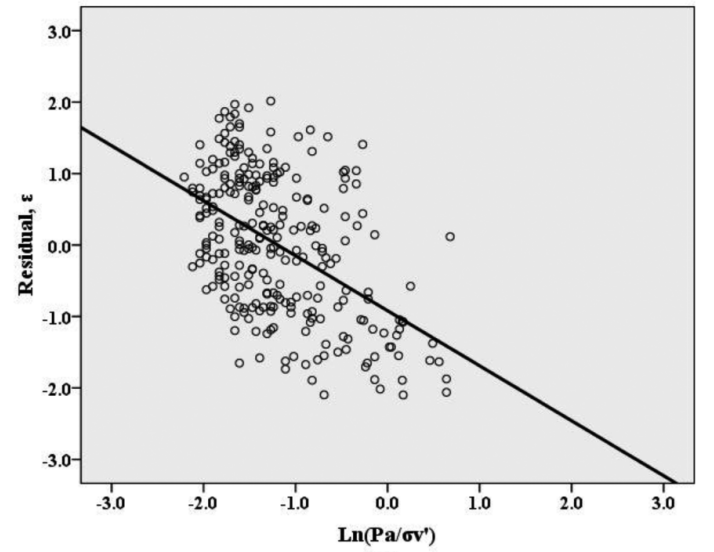

(a)

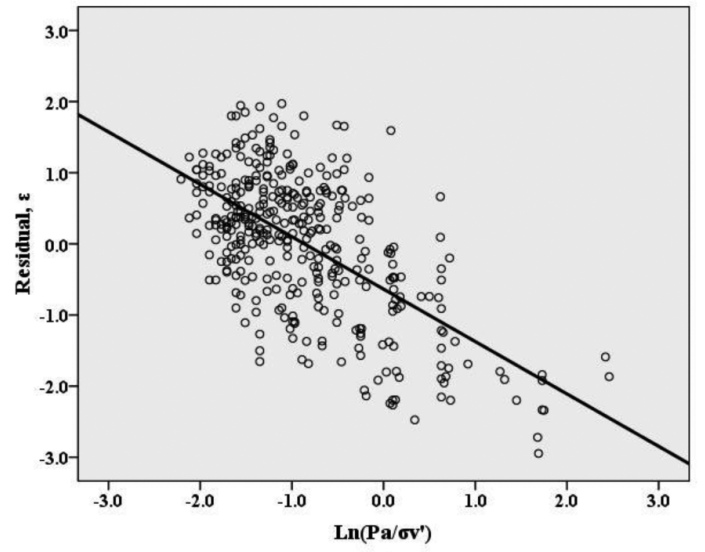

(b)

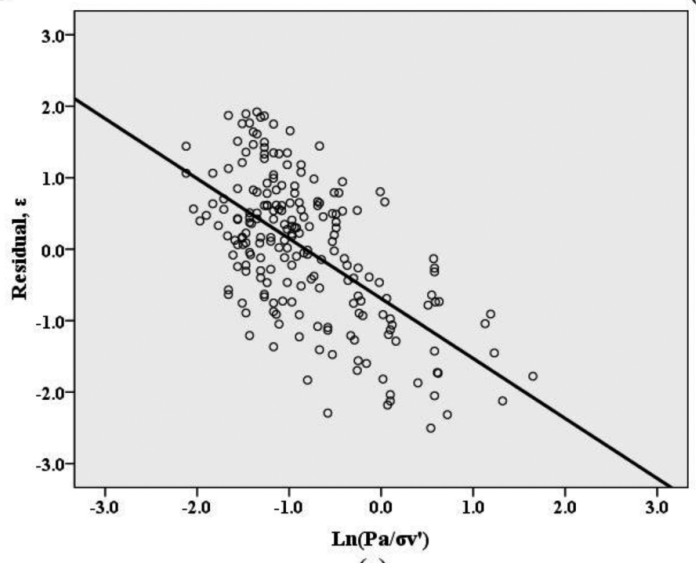

(c)

Figure 11. Residuals versus $\operatorname{Ln}\left(\frac{P_{a}}{\sigma_{v}^{\prime}}\right)$ for ordinary regression in order to show importance of effective overburden stress in $V_{s}$ estimation for (a) fine grain soil, (b) sandy soils and (c) gravely soils. 
$\sigma_{v}{ }^{\prime}$ alone rather than using $N_{60}$ alone. Brandenberg et al. [2010], Akin et al. [2011] and Ghorbani et al. [2012] were also received to the similar findings.

\subsection{Calculation of estimated $\mathrm{V}_{\mathrm{s}}^{30}$}

One of the main applications of the correlations obtained in this study is the estimation of the upper $30 \mathrm{~m} V_{s}$ of the ground, $V_{s}^{30}$, which is the main parameter in some of the Seismic code as well as Iranian seismic code (Standard No. 2800). $V_{s}^{30}$ is the most important parameter in Standard No. 2800 to classify the site conditions into the four categories (Table 5). For this, among the available databases, boreholes greater than $30 \mathrm{~m}$ in length ( 84 boreholes) were chosen to check the accuracy of $V_{s}^{30}$ estimations. Both of measured $V_{s}^{30}$ and estimated $V_{s}^{30}$ for $V_{s}$ profile measured directly and $V_{s}$ profile estimated by Equation (7), Equation (8) and Equation (9) were computed from the time taken by the $V_{s}$ to travel from depth of $30 \mathrm{~m}$ as:

$$
V_{s}^{30}=30 / \sum_{i}^{n} d /\left(V_{s}\right)_{i}
$$

where $d$ is the layer thickness or tributary length assigned to the estimated $V_{s}$ and $n$ is the number of layer or the number of $V_{s}$ values estimated along the upper $30 \mathrm{~m}$ of the ground.

We compared the measured $V_{s}^{30}$ and the estimated $V_{s}^{30}$ in Figure 12. The data points are plotted between the lines of 1:0.75 and 1:1.3. As seen in Figure 12 most of the sites used in this study are located in the $V_{s}^{30}$ category of $375-750 \mathrm{~m} / \mathrm{s}$ which are classified as ground

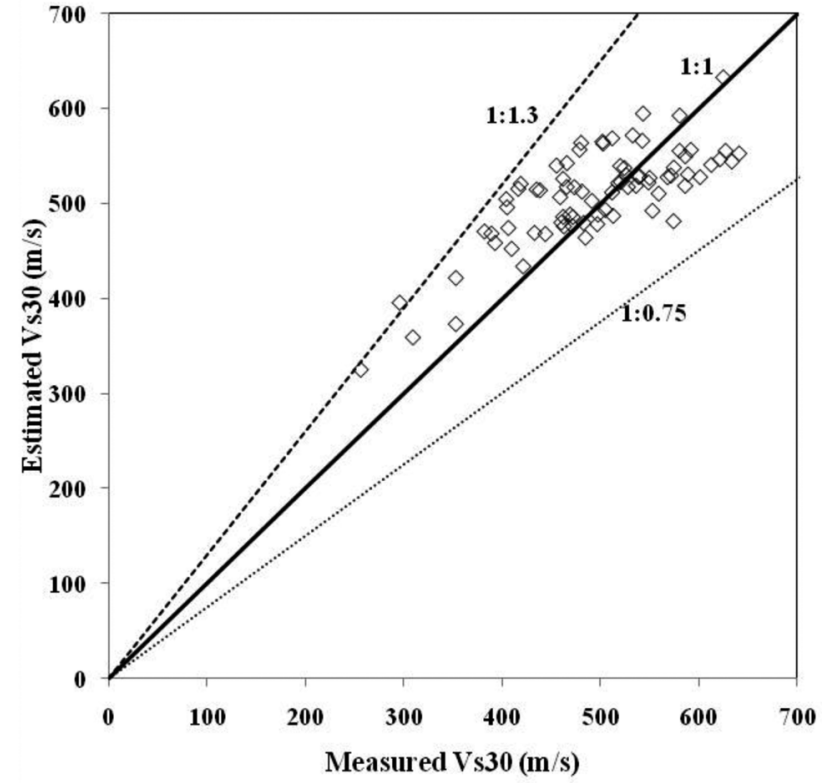

Figure 12. Estimated $V_{s}^{30}$ versus measured $V_{s}^{30}$ with lines of 1:1.3, $1: 1$ and 1:0.75 that shows good correlation between estimated and measured $V_{s}^{30}$.

type II according to the Standard No. 2800. Estimated $V_{s}$ usually tend to higher $V_{s}^{30}$. According to measured $V_{s}^{30}$, just four sites were classified as ground type III while based on estimated $V_{s}^{30}$ three of them were classified as ground type III and one site was classified as ground type II.

\section{Conclusion}

The shear wave velocity was estimated as a function of N-SPT value and effective overburden stress. Re-

\begin{tabular}{|c|c|c|}
\hline$V_{s}^{30}(\mathrm{~m} / \mathrm{s})$ & Description & Ground type \\
\hline $\begin{array}{c}>750 \\
375 \leq V_{s}^{30} \leq 750\end{array}$ & $\begin{array}{l}\text { a) Igneous rocks, stiff sedimentary rocks and } \\
\text { massive metamorphic rocks and conglomerate. } \\
\text { b) Stiff soils with a thickness more than } 30 \text { me- } \\
\text { ters above bed rock. }\end{array}$ & I \\
\hline $\begin{array}{l}375 \leq V_{s}^{30} \leq 750 \\
375 \leq V_{s}^{30} \leq 750\end{array}$ & $\begin{array}{l}\text { a) Loose and decomposed rocks due to weath- } \\
\text { ering. } \\
\text { b) Stiff soils having a thickness more than } 30 \\
\text { meters above bed rock. }\end{array}$ & II \\
\hline $\begin{array}{l}175 \leq V_{s}^{30} \leq 375 \\
175 \leq V_{s}^{30} \leq 375\end{array}$ & $\begin{array}{l}\text { a) Rocks that are disintegrated due to weath- } \\
\text { ering. } \\
\text { b) Layers of sand and gravel with medium } \\
\text { compaction. }\end{array}$ & III \\
\hline$<175$ & $\begin{array}{l}\text { a) Soft deposits with high moisture content. } \\
\text { b) Any soil profile containing clay with a thick- } \\
\text { ness of more than } 6 \text { meters. }\end{array}$ & IV \\
\hline
\end{tabular}

Table 5. Soil profile classification according to Iranian seismic code of practice (Standard No. 2800). $V_{s}^{30}$ is $V_{s}$ averaged over the top $30 \mathrm{~m}$ of the ground. 
gression relationships were obtained based on these parameters for gravel, sand and fine grain soils. The database has been compiled from 130 boreholes and totally 1500 data cases. Existing relationships around the world were reviewed which proposed the $V_{s}$ as a function of different parameters. The majority of previous studies evaluated the $V_{s}$ as a function of SPT-N alone. Most of the recent studies have investigated the effects of other parameters such as type soils, total overburden stress, effective overburden stress, depth and depositional age on the prediction of $V_{s}$. The results of this study indicate the neglecting of $\sigma_{v}{ }^{\prime}$ in $V_{s}$ estimation would be tended to the significant errors. In this paper, the impact of fine percent was assessed regardless of soil types, and three curves were determined for graphical estimating of $V_{s}$. Obtained $V_{s}$ from these curves should be multiplied by $\mathrm{K}$ coefficient which differs by variation of $\frac{P_{a}}{\sigma_{v}}$ ratios.

Acknowledgements. This research was supported by Zamin Physic Pouya engineer consulting company and authors would like to thank this support. We gratefully acknowledge the editor, Francesca Bianco, and two anonymous reviewers for comments and suggestions that significantly improved the manuscript. We would like to thank Reza Khajavi for his helpful editing and comments.

\section{References}

Akin, M.K., S. Karamer and T. Topal (2011). Empirical correlations of shear wave velocity $\left(\mathrm{V}_{\mathrm{s}}\right)$ and penetration resistance (SPT-N) for different soils in an earthquake-prone area (Erbba-Turkey), Eng. Geol., 119, 1-17.

Andrus, R.D., and K.H. Stokoe (1997). Liquefaction resistance based on shear wave velocity in evaluation of liquefaction resistance of soils, In: T.L. Youd and I.M. Idriss (eds.), National Center for Earthquake Engineering Research (NCEER) Workshop, Proceedings, Salt Lake, UT, 89-128.

Andrus, R.D., H. Hayati and N.P. Mohanan (2009). Correcting liquefaction resistance for aged sands using measured to estimated velocity ratio, J. Geotech. Geoenviron. Eng., 135 (6), 735-744.

ASTM (2008). Standard test methods for downhole seismic testing, Annual book of ASTM standard, D7400, vol. 04.09

BHRC, Building and Housing Research Center (2005). Iranian code of practice for seismic resistant design of buildings, Standard No. 2800-05, 3rd edition, Building and Housing Research Center, Tehran, Iran.

Borcherdt, R.D. (1994) Estimates of site depending response spectra for design methodology and justifications, Earthquake Spectra, 10 (4), 617-654.

Brandenberg, S.J., N. Bellana and T. Shantz (2010). Shear wave velocity as a statistical function of stan- dard penetration test resistance and vertical effective stress at Caltrans bridge sites, Soil Dyn. Earthquake Eng., 30, 1026-1035.

Campbell, K., and C. Duke (1976). Correlations among seismic velocity, depth and geology in the Los Angeles area. School of Engineering and Applied Science Report ENG-7662, University of California, Los Angeles.

Dobry, R., R.D. Borcherdt, C.B. Crouse, I.M. Idriss, W.B. Joyner, G.R. Martin, M.S. Power, E.E. Rinne and R.B. Seed (2000). New site coefficients and site classification system used in recent building seismic code provisions, Earthquake spectra, 16 (1), 41-67.

Ghazi, A., H. Hafezi Moghadas, H. Sadeghi, M. Ghafoori and G.R. Lashkaripour (2014). Spatial Variability of Shear Wave Velocity Using Geostatistical Analysis in Mashhad City, NE Iran, Open J. Geol., 4, 354-363.

Ghorbani, A., Y. Jafarian and M.S. Maghsoudi (2012). Estimating shear wave velocity of soil deposits using polynomial neural networks: Application to liquefaction, Comput. Geosci., 44, 86-94.

Hamilton, F. (1971). Elastic Properties of Marine Sediments, J. Geophys. Res., 76, 579-604.

Hardin, B., and F. Richart (1963). Elastic wave velocities in granular soils, J. Soil Mech. Found. Div., 89, 33-65.

Hasancebi, N., and R. Ulusay (2007). Empirical correlations between shear wave velocity and penetration resistance for ground shaking assessments, Bull. Eng. Geol. Environ., 66, 203-213.

Hayati, H., and R.D. Andrus (2009). Updated liquefaction resistance correction factors for aged sands, J. Geotech. Geoenviron. Eng., 135 (11), 1682-1692.

Imai, T., and Y. Yoshimura (1970). Elastic wave velocity and soil properties in soft soil, Tsuchito-Kiso, 18 (1), 17-22 (in Japanese).

Imai, T., and K. Tonouchi (1982). Correlation of $\mathrm{N}$-value with S-wave velocity and shear modulus, Proceedings of the 2nd European symposium on penetration testing, 57-72.

Iyisan, R. (1996). Correlations between shear wave velocity and in-situ penetration test results, Chamber of Civil Engineers of Turkey, Teknik Dergi, 7 (2), 1187-1199 (in Turkish).

Jafari, M.K., A. Asghari and I. Rahmani (1997). Empirical correlation between shear wave velocity (Vs) and SPT-N value for south of Tehran soils, Proceedings of 4th International Conference on Civil Engineering (Tehran, Iran), (in Persian).

Jafari, M.K., A. Shafiee and A. Razmkhah (2002). Dynamic properties of fine grained soils in south of Tehran, Journal of Seismological Earthquake Engineering, 4, 25-35.

Kanai, K. (1966). Improved empirical formula for the 
characteristics of strong earthquake motions, Proceedings, Japan Earthquake Engineering Symposium, Tokyo, 1-4.

Kokusho, T., and Y. Yoshida (1997). SPT N-value and Swave velocity for gravelly soils with different grain size distribution, Soils Found, 37 (4), 107-113

Lawrence, F.V. (1965). Ultrasonic shear wave velocities in sand and clay, Research Report R65-05, Massachusetts Institute of Technologv, Cambridge, Mass.

Lee, S.H. (1990). Regression models of shear wave velocities, J. Chin. Inst. Eng., 13, 519-532.

McGregor, J., and J.M. Duncan (1998). Performance and use of the standard penetration test in geotechnical engineering practice, Report of CGPR. Virginia Polytechnic Institute and State University, Virginia.

Ohba, S., and I. Toriumi (1970). Dynamic response characteristics of Osaka Plain, Proceedings of the Annual Meeting, A. I. J. (in Japanese).

Ohta, Y., and N. Goto (1978). Empirical shear wave velocity equations in terms of characteristic soil indexes, Earthquake Eng. Struct. Dynam., 6, 167-187.

Pitilakis, K., D. Raptakis, K.T. Lontzetidis, T. Vassilikou and D. Jongmans (1999). Geotechnical and geophysical description of Euro-Seistests, using field and laboratory tests, and moderate strong ground motions, J. Earthquake Eng., 3, 381-409.

Sakai, Y. (1968). A study on the determination of SWave velocity by the soil penetrometer test (in Japanese; translated by J. Inove).

Saran, S. (1996). Analysis and design of substructures, Balkema, Rotterdam.

Shibata, T. (1970). Analysis of liquefaction of saturated sand during cyclic loading, Disaster Prevention Res. Inst. Bull., 13, 563-570.

Sykora, D.E., and K.H. Stokoe (1983). Correlations of in-situ measurements in sands of shear wave velocity, Soil Dyn. Earthq. Eng., 20, 125-136.

Uma Maheswari, R., A. Boominathan and G.R. Dodagoudar (2010). Use of surface waves in statistical correlations of shear wave velocity and penetration resistances of Chennai Soils, Geotech. Geol. Eng. Int. J., 28, 119-137.

Youd, T.L., I.M. Idriss, R.D. Andurus, I. Arango, G. Castro, J.T. Christian, R. Dobry, W.D.L. Finn, L.F. Harder, M.E. Haymes, K. Ishihara, J.P. Koester, S.S.C. Liao, W.F. Marcusson, G.R. Martin, J.K. Mitchell, Y. Moriwaki, M.C. Power, P.K. Robertson, R.B. Seed and K.H. Stokoe (2001). Liquefaction resistance of soils: summary report from the 1996 NCEER and 1998 NCEER/NSF Workshops on Evaluation of Liquefaction Resistance of Soils, J. Geotech. Geoenviron., 127 (10), 817-833.
Corresponding author: Azam Ghazi, Ferdowsi University of Mashhad, Department of Geology, Mashhad, Iran; email: azam.ghazi@stu-mail.um.ac.ir.

C 2015 by the Istituto Nazionale di Geofisica e Vulcanologia. All rights reserved. 